Article

\title{
Fit for the Future? A New Approach in the Debate about What Makes Healthcare Systems Really Sustainable
}

\author{
Matthias Fischer \\ Institute for Sustainability Governance, Leuphana University of Lüneburg, Scharnhorststraße 1, \\ 21335 Lüneburg, Germany; E-Mail: Matthias.Fischer@leuphana.de; Tel.: +49-4131-677-1583; \\ Fax: +49-4131-677-2819
}

Academic Editor: Helmut Haberl

Received: 26 May 2014 / Accepted: 24 December 2014 / Published: 30 December 2014

\begin{abstract}
As healthcare systems face enormous challenges, sustainability is seen as a crucial requirement for making them fit for the future. However, there is no consensus with regard to either the definition of the term or the factors that characterize a "sustainable healthcare system". Therefore, the aim of this article is twofold. First, it gives examples of the existing literature about sustainable healthcare systems and analyzes this literature with regard to its understanding of sustainability and the strengths and weaknesses of the different approaches. The article then identifies crucial factors for sustainable healthcare systems, and the result, a conceptual framework consisting of five distinct and interacting factors, can be seen as a starting point for further research.
\end{abstract}

Keywords: sustainable healthcare systems; definition; conceptual framework

\section{Introduction}

In 2007, Coiera and Hovenga [1] divided the main obstacles that healthcare systems need to cope with in the medium term into four specific challenges. First, new technology and treatments have initiated technology-driven demand while at the same time creating inappropriate and wasteful health care interventions. Second, the growing expenditures for meeting the needs of an aging society have created demographic-driven demand challenges. Third, workforce capacity and funding challenges have been caused both by less workers contributing to the system's services and by significant shortages in the health workforce. Fourth, quality and safety challenges demand both an increased quality of health services and advanced elements of preventive healthcare so that illnesses can be prevented before they emerge. 
Although Coiera and Hovenga [1] referred explicitly to the Australian healthcare system, one could interpret the situation in Europe today in a similar way, as reports of the European Commission [2,3] have highlighted. Generally, there seems to be, on the one hand, an increasing demand for high-quality healthcare, and, on the other hand, a need for efficiency because of limited financial resources and higher costs due to technological advancements and demographic changes.

Sustainable development has been defined in two distinct ways by the World Commission on Environment and Development's groundbreaking report "Our Common Future" from 1987 chaired by Gro Harlem Brundtland (and therefore referred to as "Brundtland Commission" and "Brundtland report" in the following): First, as a "development that meets the needs of the present without compromising the ability of future generations to meet their own needs" [4] (p. 41), and second, as "process of change in which the exploitation of resources, the direction of investments, the orientation of technological development, and institutional change are all in harmony and enhance both current and future potential to meet human needs and aspirations" [4] (p. 43). The report highlighted the need to analyze current problems as interplay between economic, social, and ecological factors that need to be jointly addressed. Consequently, based on the challenges that healthcare systems face, one would expect that a focus on sustainable development would be in the center of considerations about healthcare systems.

However, a review of existing health performance frameworks conducted by Arah et al. [5] revealed that sustainability is seen only as one performance dimension among others-if considered at all. In addition, neither is there a consensus on the term "sustainable healthcare system" (the understanding of sustainability and sustainable development is the same in this article and can be used interchangeably, as it was done by previous research [6]), nor is it sufficiently clarified what factors are characterizing such a system. This paper contributes to the steadily growing scientific literature by giving an overview of the state-of-the-art research and at the same time by moving a step forward: The aim is to describe a sustainable healthcare system based on exemplary pieces of previous research and the author's own considerations. Therefore, this paper is structured in the following way. First, the article gives a short overview of the methods used to find relevant studies, followed by an overview of definitions of "sustainable healthcare systems". Then, six exemplary approaches are analyzed, each representing different research directions. Afterwards, the article develops a conceptual framework to characterize sustainable healthcare systems. A final discussion summarizes the main points and classifies the findings with regard to limitations and proposals for further research.

\section{Methods}

In order to achieve the aim of an integrating framework, an electronic literature and project review was performed in order to identify and classify relevant studies about research on sustainable healthcare systems. Potential contributions were identified through the use of a combination of keywords related to the topics "sustainability/sustainable development" and "healthcare systems" and the German equivalents "Nachhaltigkeit/Nachhaltige Entwicklung" and "Gesundheitssysteme/Gesundheitswesen", respectively. The search engines "Google" and "Google Scholar" were used as sources of information for two reasons: First, they allowed the author to find and include a broad variety of articles and projects because using a more restrictive search might have failed to retrieve all possible articles of interest. Second, these search engines also located practical and transdisciplinary projects by non-academic think-tanks or lobby 
groups, which contribute, in numerous and often unrelated ways, to the debate on sustainable healthcare systems by offering, for instance, specific policies or guidelines. The literature search revealed that projects and articles about sustainable healthcare systems could be arranged in the following order (Figure 1).

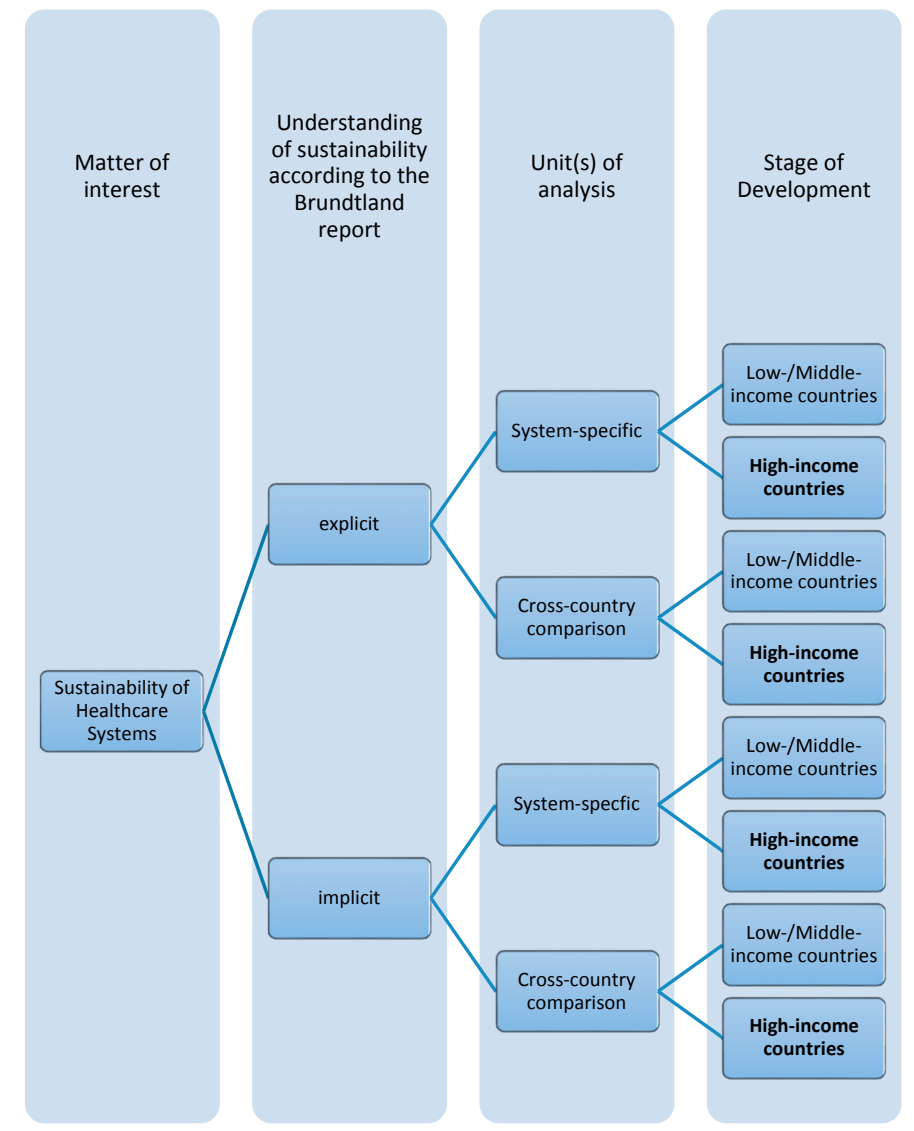

Figure 1. Different ways of analyzing healthcare sustainability.

First, research dealing with sustainability of healthcare systems was categorized as either explicitly or implicitly referring to understanding of sustainability of the Brundtland report. Explicit reference to this definition meant that both the long-term perspective and the three distinctive and interdependent components of sustainable development (economic, social, and ecological) were taken into account by the research projects. Research projects that did not explicitly refer to the Brundtland definition had to point out at least the importance of taking the needs of future generations into account when thinking about sustainability. Often, however, these approaches did not display a deeper understanding of the three pillars of sustainability. Second, research activities were differentiated by the question of whether the study or project aimed to analyze healthcare systems by a cross-country comparison or by a deeper analysis of a single healthcare system (which could also be conducted on a more abstract level, of course). The third differentiation was made between approaches targeting highly industrialized, high-income countries and their healthcare systems, and low- as well as middle-income countries. Analyzing countries with a history of high standards in healthcare for decades is different from the perspective of analyzing countries creating a system during a period of rapid economic growth and tremendous social changes or countries with a healthcare system that does not function yet [7]. As fundamentally different analysis paths are required for each, only approaches that targeted high-income countries were considered for this study. 
Based on this structure, exemplary approaches of each category will be presented below. One may criticize that the approaches discussed here do not cover the full range of existing approaches, and deservedly so. Hudson and Vissing [8] found out that already more than one thousand articles have been published on "health" and "sustainability" since 1977 (for a more detailed literature review about sustainability and healthcare systems, see also: Mackay and Wolbring [9]). However, the following sections are explicitly not intended to offer an exhaustive analysis, but to provide a survey of contributions that shows how research about the topic was performed from different directions and how the strengths and weaknesses of each model can be characterized, just in order to develop a new framework afterwards, which is expected to include the most relevant criteria of sustainable healthcare systems. The exemplary approaches presented here suggest the broad variety of approaches in this steadily growing research field on sustainable healthcare systems, a term that will be defined in the following section.

\section{Defining Sustainable Healthcare Systems}

Healthcare systems can be defined as "all the activities whose primary purpose is to promote, restore and maintain health" [10] (p. 5), with health being a state of complete physical, mental, and social well-being and not merely the absence of disease or infirmity [11]. Healthcare systems are described as very complex systems that consist of many stakeholders [12]. In addition, it must be also taken into account that healthcare is an open system that has a dynamic interdependency with other social and environmental factors [1].

Similar to the unclear boundary separating healthcare systems from other societal systems, there is still no general definition of sustainable healthcare systems, which is one of the reasons why Muzyka et al. [13] stated that "not everyone means the same thing when they speak about 'sustainable health care"". For example, many economic papers have a tendency to call a healthcare system sustainable if long-term financial stability is guaranteed [14-16]. However, financial stability is only one of the three interdependent and mutually reinforcing pillars identified by the Brundtland Commission. Therefore, Jameton and McGuirre [17] defined sustainability in healthcare as a balance of the needs of patients, economic concerns, and environmental costs. This definition points out that patients are the primary focus and therefore at the center of healthcare systems, but it tends to omit another important stakeholder, namely healthcare personnel. Schön [18] filled this gap by transferring the three-pillar model to the context of a sustainable healthcare system. He also included the needs of the healthcare workforce. The Alliance for Natural Health defined the term sustainable healthcare system in a similar manner, suggesting that it refers to a "complex system of interacting approaches to the restoration, management, and optimization of human health that has an ecological base, that is environmentally, economically and socially viable indefinitely, that functions harmoniously both with the human body and the non-human environment, and which does not result in unfair or disproportionate impacts on any significant contributory element of the healthcare system" [19] (p. 9).

Due the complexity of existing problems, sustainability science over the past ten years has developed approaches that step away from the clear distinction between the three pillars and towards the application of an integrated approach with cross-section terms, such as intergenerational justice, quality of life, or social cohesion [20]. Prada's [21] (p. 8) definition can be seen as one step in this direction, as it defines a sustainable healthcare system as "a system that is designed to meet the health and health care needs of 
individuals and the population (...); leads to optimal health and health care outcomes; responds and adapts to cultural, social, and economic conditions and demands; and does not compromise the outcomes and ability of future generations to meet their own health care needs". This definition does not, however, explicitly address the importance of preserving the natural environment when thinking about sustainable healthcare systems.

In spite of the different ways to define sustainable healthcare systems, and regardless of whether the three-pillar model or the integrated understanding of sustainability is applied, all approaches seem to have in common that a comprehensive approach with a long-term focus and a need to balance economic, social, and ecological interests needs to be used in the discussion of sustainable healthcare systems.

\section{Characterizing Sustainable Healthcare Systems-Existing Approaches}

Following the short discussion of existing definitions of "sustainable healthcare systems", this section exemplifies the set of approaches to sustainable healthcare systems listed in the "method" section of this article (Figure 1), as it can be seen by the respective headlines. Regarding the system-specific approaches, two examples will be presented, one of them providing a more theoretical and the other one a more applied perspective.

\subsection{System-Specific Approach with an Explicit Reference to the Brundtland Report}

Faezipour and Ferreira [6] applied the perspective of systems thinking and systematically reviewed the literature about sustainable healthcare systems. They developed six major categories of healthcare sustainability: "Patient" and "Quality" representing the social; "Provider", "Resource", and "Financial" representing the economic; and "Environmental issues/Energy" representing the ecological pillar. Based on the assumption that all six categories are interrelated, they created a systems thinking cause model that includes these six key categories and their additional specifications. From a sustainability point of view, it is notable that they explicitly highlighted the cost of managing environmental waste as part of the financial category, thereby showing how interdependent these categories actually are. Currently, Faezipour and Ferreira [22] are in the process of validating their causal model by qualitatively assessing the causal relations within a set of hospitals in the United States. It will be interesting how many of the proposed relationships will be proved by their research.

An approach with a more concrete application has been developed by Schön [18]. Based on the definition given in the Brundtland report, he identified eleven criteria that he regards as crucial for a sustainable healthcare system (see Table 1).

With these criteria, Schön presented a seemingly convincing concept and announced the need for interdisciplinary networking and research in order to identify relevant goals for a sustainable healthcare system in Switzerland; however, it does not seem that these suggestions were followed up by further research projects. Moreover, some of the eleven criteria are expressed quite vaguely, for example, the tenth statement that does not allow for concrete measurements. Furthermore, Schön developed his approach in the specific context of Switzerland, so the eleventh statement, for example, which calls for the establishment of a new institution in Switzerland, cannot be generalized without adapting it to a broader context. 
Table 1. Criteria for a sustainable healthcare system following Schön [18].

(1) Securing long-term financing; respecting ethical norms regarding individuals, social structures and the environment; and guaranteeing high-quality development through both innovative research and the inclusion of practical experience.

(2) Neither favoring particular interest groups nor being focused on short-term election periods.

(3) Stimulating the skills of the individual (compliance and empowerment) through education and improved information channels (internet).

(4) Taking direct and indirect prevention into account, the latter meaning improved general health (not only healthcare) conditions.

(5) Better integrating the resources of all actors included.

(6) Offering transparency with regard to uncovering hidden lobbying activities, cultivating interdisciplinary discussions, and providing efficient bureaucracy so that the medical workforce can concentrate on their actual tasks.

(7) Considering the legitimate occupational demands of the various stakeholders, meaning not only improvements in payment but in their personal development through better appreciation and an adaption with regard to continuing training.

(8) Appreciating scientific and technical innovation for a qualitative improvement in performance and reducing administrative barriers, for example by using the potential of e-health communication technology.

(9) Fostering scientific transfer and engagement for sustainable development in low-income countries, taking global interconnectedness into account.

(10) Addressing ecological issues, which goes without saying.

(11) Fostering information exchange, doing research, and developing future strategies within a yet-to-be-established institution for a sustainable healthcare system.

\subsection{Cross-Country-Comparison Approach with an Explicit Reference to the Brundtland Report}

There have been approaches that regard "health" as an essential part in more general assessments of sustainable development and the possibility to compare the development of countries over time. One example is the European Union Sustainable Development Strategy whose implementation has been evaluated by using a set of "indicators for sustainable development" since 2007, where "public health" is one of 10 core dimensions that monitor sustainable development both on the level of EU member states and the European level. Within the "public health" dimension, "life expectancy and healthy life years" is serving as the headline indicator. In addition, the subchapter "health and health inequalities", with its indicators "deaths due to chronic diseases", "suicides", and "unmet needs for healthcare", and the second subchapter "determinants of health", which is described by the indicators "production of toxic chemicals", "exposure to air pollution by particulate matter", "annoyance by noise" and "serious accidents at work" provide more detailed information concerning selected determinants of public health sustainability [23].

It is important to note that the indicators do not merely cover direct outcomes of the healthcare system, but also include more general social and environmental factors, for example the negative influences of noise, work accidents, or toxic chemicals. Although these indicators may provide a good overview about sustainable development in societies over time, one could argue that sustainability in healthcare systems is not just a subsection within a general measurement of sustainable development, but must be analyzed separately and in a more detailed way. 


\subsection{System-Specific Approach with an Implicit Reference to the Brundtland Report}

Stuart and Adams [24] tried to foster the debate about reforming the Canadian healthcare system by adapting Maslow's hierarchy of needs to the context of healthcare sustainability (see Figure 2).

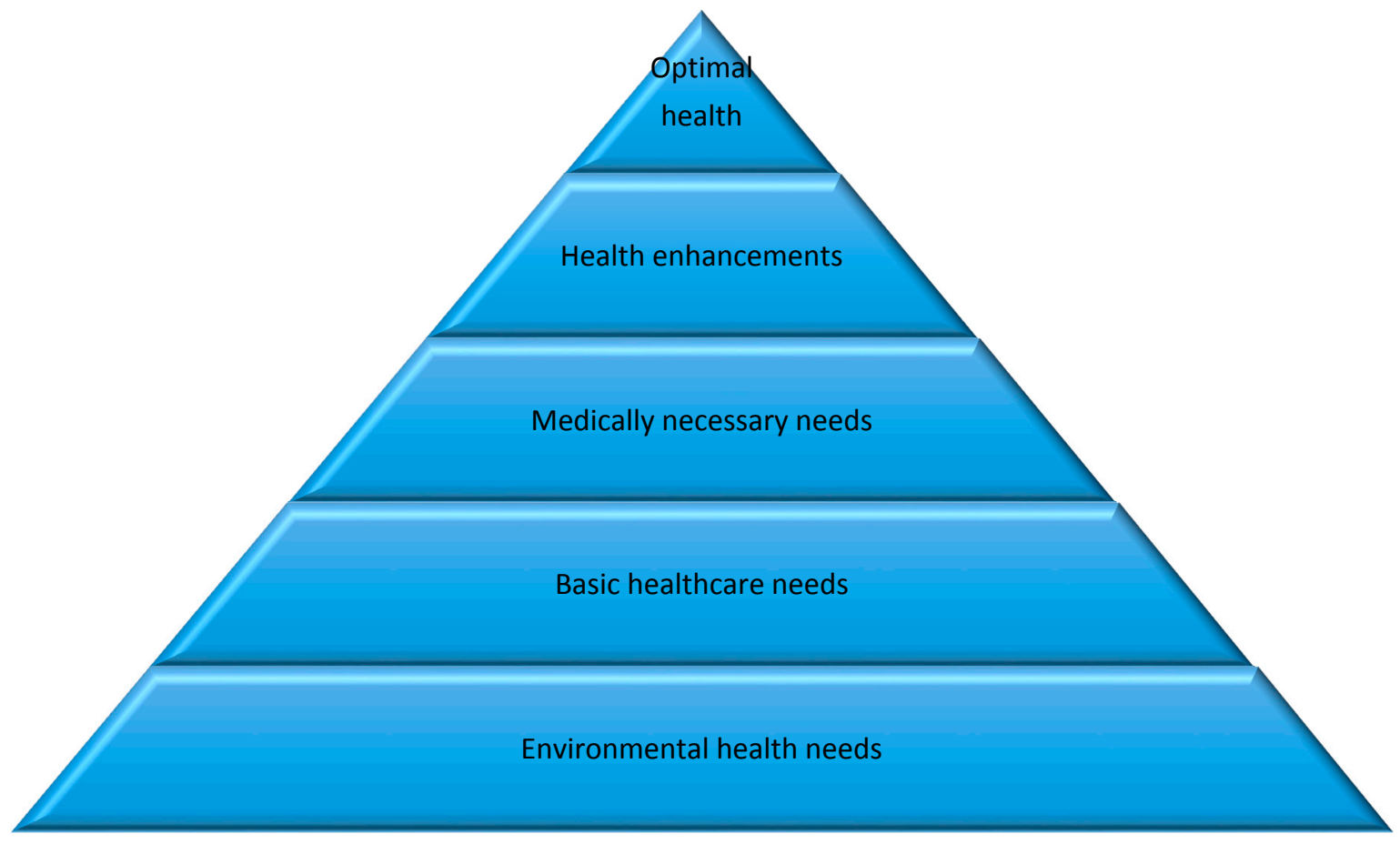

Figure 2. Pyramid of healthcare needs (taken from Stuart and Adams [24]).

According to Stuart and Adams, this pyramid, where lower needs take priority over higher ones, can be applied to both individuals and societies at different points in their development. This approach takes the complexity of healthcare systems into account and structures health needs in five categories, thereby lifting the reform debate towards sustainability on a theoretical framework and recognizing environmental health needs as crucial elements for a functioning healthcare system. Furthermore, stressing the importance of a public debate and requiring governments to take a long-term view are key points from the Brundtland report about sustainable development, although Stuart and Adams do not explicitly refer to this document.

However, Stuart and Adams's assumption that some of the lower needs are once and for all satisfied could be viewed as not very realistic. For example, the climate change's expected direct and indirect negative effects of climate change on human health are likely to become more pronounced, as, for example, heat waves will increase the number of hospital admissions especially among young children and the elderly and floods will lead to more injuries and increased morbidity [25]. Furthermore, a WHO report based on data from 2012 stated that air pollution is a significant threat for human lives even in far-developed industrialized countries [26]. Likewise, the problematic loss of biodiversity with its multiple interdependencies [27] is yet another indicator that needs cannot be satisfied one after the other, but that all of them must be continually and holistically addressed.

From a more applied perspective, Prada and Brown qualitatively assessed 18 national and provincial studies and reports that, in turn, have examined the sustainability of Canada's health care system over a period of 15 years and that all offer different recommendations [28]. In accordance with these findings, 
Prada [21] later presented crucial factors for sustainable health and healthcare systems. On the general basis of four more general quality indicators (appropriateness, fair and timely access, value for money, and accountability for results), she suggested that sustainability in healthcare systems consists of six pillars: "(1) effective disease prevention and health promotion strategies and programs; (2) effective health care system management structures, processes, and approaches; (3) affordable financial resources and investments and innovative funding models; (4) leveraging innovation and innovative technologies; (5) optimal development and alignment of human resources; and (6) effective government policies outside of health care" [21] (p. 9), for example healthy workplaces.

Prada's approach clearly outlines the main issues that seem to be relevant for sustainable healthcare systems, and it can serve as a good starting point when thinking about healthcare reforms. Furthermore, using a clear and integrated understanding of sustainability, as defined above, may allow for a deeper understanding of the complex problems and structures when it comes to sustainability in healthcare systems. However, it seems as if concerns with regard to the ecological environment as well as energy consumption, which are crucial for sustainable healthcare, are not included in Prada's approach. In addition, the specific focus on the Canadian context does not allow for a one-by-one adaptation to other contexts without generalizing the concept.

\subsection{Cross-Country-Comparison Approach with an Implicit Reference to the Brundtland Report}

In another report, entitled "Challenging Health Care System Sustainability: Understanding Health System Performance of Leading Countries", Prada et al. [29] compared the Canadian healthcare system with countries that were seen as best performers with regard to specific medical or non-medical healthcare results (e.g., Sweden, Australia, and Switzerland). As a result, they drew eight conclusions, which are briefly described in Table 2 .

Table 2. Conclusions from a cross-country healthcare performance comparison by Prada et al. [29].

(1) Performance cannot be measured by the money spent only, as high performers, such as Sweden's rank among the lowest spenders on health care.

(2) The control of publicly funded pharmaceutical costs through price controls and trainings for doctors is crucial in order to prevent escalating expenditures.

(3) Measures to promote a satisfied and productive workforce, especially beyond remuneration, are central for a high-performing system.

(4) Health promotion, prevention, and investments in broader health determinants can decrease healthcare expenditures in the long run.

(5) A high percentage of elderly people is not necessarily followed by escalating costs when integrated approaches along the continuum of care are developed and applied.

(6) Workforce productivity can also be improved by investing in health-related information and communication technologies and by offering training and skill development.

(7) User fee methods may have benefits with regard to the control of costs, but must not lead to a belated detection of symptoms because people do not consult doctors.

(8) Long waiting times must be avoided by ensuring adequate surgical capacity. 
Overall, Prada et al. stated that these best practices show several decisive cultural characteristics, namely strong and dedicated leaders, flexible and motivated workers, a public with realistic expectations of the healthcare system, and the will to improve personal health. According to their analysis, a united effort of all key players is needed [29], which can be seen as a claim for strong participatory and consensus-oriented methods and institutions.

Because of the analysis of best-practice cases, the approach offers an explanation why some countries perform better than other countries. Furthermore, this approach not only looks at financial issues, but also considers social aspects, for example concerns of the healthcare workforce or investments in broader health determinants. One could argue that the exact understanding of "sustainability" remains unclear, even if the title of the report explicitly refers to "Health Care System Sustainability". Without a clear definition, it is difficult to think about the difference between healthcare sustainability and other performance indicators, and it is not possible to judge what exactly the main predictors of healthcare sustainability are.

\section{Relevant Dimensions for Sustainable Healthcare Systems—Conceptual Framework}

Overall, the review of exemplary approaches seems to suggest that healthcare systems need to address some key factors in order to develop towards sustainability. This article proposes the following five categories: long-term strategic perspective and innovativeness; disease prevention and health promotion; quality; institutionalization of environmental concerns; as well as institutional accountability and individual responsibility.

\subsection{Long-Term Strategic Perspective and Innovativeness}

With regard to sustainability, the phrase long-term strategic perspective and innovativeness commonly reflects an economic perspective. The political actors are especially important here as they usually have the power to make decisions that fix the "rules of the game". This approach has three implications. First, a sustainable healthcare system must keep financial costs under control. Unfortunately, both researchers and policy-makers disagree on how to ensure overall economic sustainability. There is some agreement that changes with regard to both patient and provider behavior, as well as a shift of resources to activities that improve health should be promoted [28]. Moreover, healthcare providers should be encouraged to create the right incentives in order to provide a maximum value for money [13]. Escalating pharmaceutical costs need to be controlled by, for example, the use of price-controls, bulk buying, or a qualified reduction of customer demand for drugs by education campaigns [29]. The application of cost-control management procedures and a critical review of existing approaches are also crucial issues [28].

The second issue is the need for a strategic perspective among policy-makers. In a sustainable healthcare system, incremental decision-making needs to be replaced by long-term planning based on strategic deliberations. The key to strategic management is a realistic analysis of the current situation, followed by the setting of clear, long-term goals and a detailed plan of how to achieve these goals. Muddling through and patchwork repair has to be replaced by basic and lasting reforms, which balance social and financial imperatives [15], and tradeoffs in society need to be clearly communicated and discussed [13]. A sustainable healthcare system also has to be sufficiently adaptive, meaning the ability to react to changes in the inputs or outputs of the system [1]. This may be fostered, on the one hand, through 
consensus about healthcare goals and, on the other hand, through constant and participative deliberations about healthcare reforms across party lines.

The third issue is the maximization of a system's innovativeness. Scientific and technological innovativeness is at the center of this issue because such innovativeness contributes to improving healthcare services, developing effective pharmaceuticals, and reducing administrative barriers [18,28]. Staying innovative is a key for keeping the long-term ability to stay competitive. However, it also includes the search for innovative funding models. Even if there is little consensus, reforms are unavoidable. Recommendations such as strengthening the private sector, user charges, or the separation of long-term care and high-cost medical care [15], must be evaluated in the end by their ability to keep costs as low as possible without harming the social cohesion.

\subsection{Disease Prevention and Health Promotion}

Prevention and wellness programs are seen as crucial for a sustainable healthcare system [18,21]. Primary healthcare facilities are often mentioned as preferred settings for strengthening prevention and promotion activities [28]. They can also contribute to better outcomes for less money within a healthcare system [30] because they may address problems at an early stage and effectively help to prevent them. Therefore, a sustainable healthcare system needs to emphasize strong primary care facilities that allow for patient-centered, easily accessible, and comprehensive services.

Another target is the prevention of chronic diseases because a very high number of primary care visits are related to chronic diseases [31]. As patients with chronic illnesses are facing a higher risk of developing additional chronic diseases [32], a sustainable healthcare system requires effective chronic disease prevention by minimizing waiting times and providing quick and high-quality solutions for individuals concerned with or facing the risk of chronic diseases [33].

It is crucial not only to consider the overall population, but also the healthcare workforce when it comes to prevention and health promotion. The goal is to maintain a high level of staff commitment and morale, which is essential for providing high-quality service to patients. As doctors, nurses, and other healthcare professionals are frequently required to do more than they can, decreased staff morale and mental illnesses such as depression or burn-out have come to severely affect the healthcare workforce. For example, inadequate staffing levels and work overload have been studied as key determinants of clinical workforce's job turnovers [34].

Therefore, a sustainable healthcare system needs to ensure that the work hours of healthcare employees are restricted to a responsible number of hours and that the services offered receive a fair financial reward. In case of mental problems, help has to be provided quickly. In addition, a sustainable healthcare system has to guarantee that staff members are not stuck in one position for all their lives, but can develop professionally by taking advantage of training programs for life-long learning.

\subsection{Quality}

According to the Institute of Medicine's (IOM) widely accepted definition, quality can be defined as "the degree to which health care services for individuals and populations increase the likelihood of desired outcomes and are consistent with current professional knowledge" [35] (p. 21). Indicators are needed to measure quality, and following Donabedian, these indicators refer to the structure, the 
processes, and the outcomes of health services [36]. However, there are different ways how to translate the IOM's general definition in concrete imperatives [6], especially with regard to outcome indicators.

Arah et al. [5] analyzed several health and healthcare frameworks of selected countries for potential dimensions of healthcare performance, and they developed a healthcare system performance framework that was embedded in a broader health indicators framework. For them, core quality dimensions are effectiveness, safety, and responsiveness/patient-centeredness. In their review of other healthcare performance frameworks, additional performance indicators (e.g., acceptability, care environment and amenities, continuity, governance or safety) could also be found. In general, the factors used to determine quality should be the result of informed public debates about the goals and dimensions of healthcare. It was mentioned earlier that "sustainability" has been seen, if it has been considered at all, as a subsection in quality frameworks of healthcare systems. This article recognizes the important link between "quality" and "sustainability", but it argues that we need to consider "quality" as a key determinant of healthcare sustainability, because a lack of quality will lead to decreased acceptance by the population and to higher costs for the entire system in the long run.

It has become increasingly important to invest in health-related information and communication technologies (ICT) and to connect it with conventional practices [18,29]. State-of-the-art technology has to be standard in all facilities, so that data can be analyzed effectively-more and more important is the structured analysis of big data - and a continual assessment of its impact on patient care can be conducted. Variation in healthcare and the related issues of over-treatment and under-treatment are not only problems on a global scale [37], but also a major concern within countries: Thus, the goal of health policy has to be the reduction of unwarranted variation: The distribution of the burden of paying for services as well as the distribution of healthcare and its benefits needs to be carefully monitored, and governments need to address inequalities, for example by setting region-based targets and re-allocating resources in regions with low utilization rates, or by implementing changes in payment systems in order to stipulate lower use in areas where a high suspicion of overuse exists [38]. Of course, equitability is also a matter of accessibility. In a sustainable healthcare system, local supply for all patients needs to be guaranteed, and patients should be served according to their needs [18]. This also includes the reduction of waiting times, which greatly affect the way a given population perceives the general quality of the system, and the non-discrimination of minorities, such as ethnic minorities, immigrants, people with special needs, or the elderly, depending on the region or state [28].

\subsection{Institutionalization of Environmental Concerns}

This article argues that two kinds of environments must be taken into account in order to establish a holistic view of what determines a sustainable healthcare system: First, the overall social environment, and secondly, the overall ecological environment. The connection between the two can, for example, be seen in discussions of environmental justice, that is, of instances when a social group is disproportionately affected by environmental hazards and subsequent negative health consequences, which, in turn, lead to health inequalities within societies [39]. It has been observed in sustainability science that the existence of certain values is not necessarily followed by concrete measures [40]. In order to overcome this gap between consciousness and actual decision-making, it is crucial to walk the talk and to proceed towards the concrete institutionalization of sustainability in (health) policy-making [41]. 
The first kind of environment is reflected in the integration of social issues, which is called, following Schön's definition [18], "indirect prevention" in this article. As healthcare is an open system [1] with many interdependencies, it is necessary to consider factors outside of the healthcare system. The assumption of Dahlgren and Whitehead $[42,43]$ that not only individual behavior but also community networks, as well as general socio-economic, cultural, and environmental conditions shape human health, helps us to understand the importance of indirect prevention and it corresponds to the holistic nature of the Brundtland report [4].

In order to shape a sustainable healthcare system, broader socio-economic and cultural determinants of health such as education, early childhood development, income, and social status [29] as well as interdependencies with families, community organizations, and employers [13] have to be taken into account. In order to institutionalize these developments, one could think of a "Health Impact Assessment" of political measures in the different policy areas, similar to the Regulatory Impact Assessment (“Gesetzesfolgenabschätzung") as it exists in Germany, for example, or the Integrated Impact Assessment on the European level [44].

Even in industrialized countries, environmental risk factors are still said to contribute to an average of $16 \%$ of the burden of disease (measured in healthy life years lost), and may result, for example, in chronic obstructive pulmonary diseases, cardiovascular diseases, or asthma [45]. Often, a vicious circle can be observed: Environmental decline requires medical treatment, which again damages the natural environment, for instance in the form of medical waste, especially disposable items [46] as well as infectious materials and biohazardous agents, such as heavy metals and radioactive isotopes. Medical treatments also commonly lead, to give but one more example, to a high energy demand. The consumption of pharmaceuticals is expected to increase in the next years, and although it contributes to a higher standard of living, the production, application, and disposal are likely to cause heavy pollution of the environment and serious health hazards [47]. Furthermore, the general and often irreversible loss of biodiversity in many societies is posing serious threats to public health, as links between human and natural health become more and more obvious: Biodiversity plays a role in safeguarding air quality and fresh water, can reduce the risk of infectious disease spread and may stimulate social life, thereby reducing stress reduction, encouraging physical activity and increasing personal development [27]. In addition, the importance of biodiversity for the production of pharmaceuticals and other medical practices has been stressed $[48,49]$, although the relation between biodiversity and human health is complex and may sometimes also be negative [50].

Thus, in a sustainable healthcare system, the ecological environment must be recognized and addressed as a crucial factor. Following Schön [18], one could argue that the negative impact of the consumption of natural resources needs to be minimized at any time, for example by developing effective and efficient treatments that can reduce environmental waste. The reduction of pharmaceuticals, as discussed by Götz and Deffner, is a case in point: Every stakeholder involved in healthcare could contribute to a more conscious use of pharmaceuticals, and a three-pronged approach involving different stakeholders seems to be the most promising: Political measures (e.g., environmental objectives), communication measures (e.g., awareness-raising among the professional stakeholders), and measures to facilitate changes in patient behavior (e.g., prescription options that prevent the use of drugs or the introduction of co-payment) all need to be part of the solution [51]. The trend towards more disposable items has been topic for quite a while already [46] and needs to be challenged by the development of effective take-back systems and 
the development of reuse possibilities without affecting the health of patients [52]. The goal should be to provide a solution for the increasing and at times unnecessary use of one-way items. In medical settings, water and energy consumption need to be highly efficient, and renewable energies should be the primary energy source. This is not about not using non-renewable resources anymore, but about their conscious usage. In addition, the introduction of green healthcare facilities should be promoted, and the healthcare workforce needs to be educated about acting environmentally friendly. In general, the interdependence of the natural and social environments with regard healthcare must be recognized and respected, and this understanding needs to be translated into health policy-making.

\subsection{Institutional Accountability and Individual Responsibility}

In order to ensure a high acceptance by the population, in order to ensure a long-term stability of the entire system, and last but not last in order to decide how to transform the society and what resources it agrees to finally invest, the question of accountability emerges. This also includes the debate about what the individual needs to sacrifice in order to stabilize the whole system. Therefore, the concept of accountability in this article is threefold.

First, it means that a sustainable healthcare system should be transparent with competencies that are clearly distributed [18]. Because healthcare systems are publicly funded, it is crucial to make clear where the money goes to and who is responsible for what and to what extent in order to gain public acceptance. Furthermore, as it was already shown that higher expenditure is not directly related to better healthcare outcomes [29,53], the question arises if better accountability could not only produce more efficient results but also clear away obviously inefficient structures and shift resources to other parts of the system that are recognized as more urgent through better transparency.

Second, accountability means the importance of including many stakeholders in the decision-making process. The need for participation was seen as especially important for sustainable development not only with regard to the actual decision-making, but also with regard to a permanent discussion within society about common aims for future development [54]. Much of the literature stresses the importance of taking the population into account in order to mobilize support for changes among all stakeholders within the healthcare system, which is needed to finally accept the trade-offs that societies are supposed to make in the future $[12,55]$.

Third, the requirement to empower patients aims at enabling them to take ownership of their individual health $[13,18]$, a principle that is based on liberal political ideas and the observation that improvements in information and communication technology have contributed to well-informed patients who have higher demands for better information and are less dependent on professional gatekeepers [2]. This can be done by providing direct information as well as communicating the need to patients to accept responsibility for their own health. It does not necessarily mean the privatization of the entire healthcare system, but it emphasizes that a sustainable healthcare system should rely on the maturity and the will of its patients to care about their lives on their own and partly without the social framework.

\section{Discussion and Conclusions}

Thinking about sustainability in healthcare systems is a key task for both policy-makers and researchers as they are facing huge social, financial, and ecological pressures and challenges. In this article, exemplary 
approaches regarding sustainability in healthcare systems were reviewed, and a conceptual framework outlined the five major categories that seem to be most important for healthcare sustainability (Figure 3).

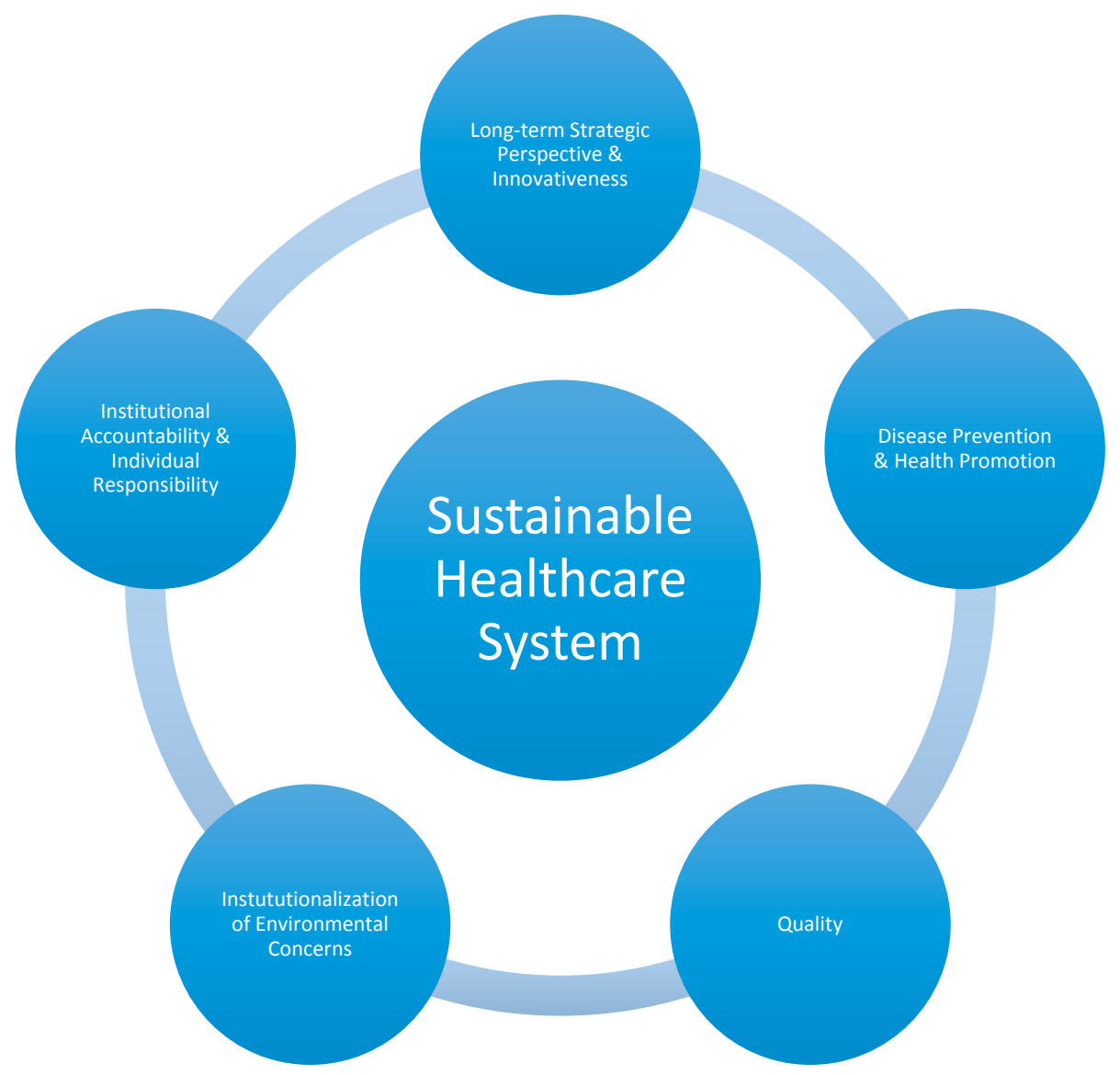

Figure 3. Relevant dimensions of healthcare system sustainability.

In order to structure the framework with regard to the definition of sustainability used here, it offers an integrated approach that includes all three pillars of sustainable development within five distinct categories that are highly interdependent. Efficiency of treatments, for example, will probably lead to lower costs and contribute to financial stability in the long run as well as to lower energy consumption. Improvements in indirect prevention often also promote health. The more general headlines of the categories summarize the most important recommendations that may guide policy-makers when they plan, prepare, and implement healthcare reforms. Through continuous assessment, strategic planning, and the use of quality indicators as outcome-based maxims, as proposed in this article, policy-makers are encouraged to constantly consider the multiple causal and dynamic factors that constitute healthcare systems so that progress can be achieved, as "sustainable healthcare systems will depend fundamentally on learning mechanisms built into the system to enable continual improvement and adaptation through time" [55] (p. 27). If this goal were to be achieved, a sustainable healthcare system could be an important step toward a "sustainability state" on a more general level [41].

Two aspects that were identified as important for healthcare sustainability in some of the literature were not addressed in this framework: First, Schön [18] and Mohrman et al. [56] stressed the global perspective of sustainable development and concluded that global interconnectedness must result in the 
necessity to transfer knowledge and resources as part of development cooperation with low-income countries. Although this emphasis on the importance of global networks is warranted, this article's concept sees "Think globally, act locally" as the central claim for sustainable development, and it argues that introducing sustainable development in a nation's healthcare system may already have a large impact. Second, this article supported Grunwald and Kopfmüller's [20] claim that normative requirements for the assessment of sustainable development should not only be conducted by scenario analyses looking into the future, but also by comparing today's situation with the past in order to get an improved basic understanding for future development. Therefore, this article does not aim to provide a scenario analysis that depicts how healthcare systems might look like in the future, but it aims to describe normative requirements from today's point of view. In 2012, the World Economic Forum already developed scenarios of what healthcare systems could possibly look like in 2040, "demonstrating that radically different health systems are imaginable" [57] (p. 3).

Overall, the framework is not designed in order to replace former concepts of healthcare sustainability but rather to assess the growing number of approaches and to synthesize them with regard to top-level categories by improving their weaknesses and by keeping their strengths. It combines existing approaches and future-oriented thinking. While the categories are fairly general, they could still be used in a variety of specific contexts. The framework could be applied in both national and international contexts for the assessment of sustainability.

Further research on these contexts is still needed. First, a deeper insight in the complex causal relationships within the healthcare sector is needed. First research activities in this direction can already be observed [22]. At the same time, it would be necessary to investigate to what extent the differentiated understandings of sustainability in healthcare systems are already available in contemporary political structures and processes. One could assume that politicians are often restricted by short-term election periods and an understanding of sustainability limited to economic issues. The author of this article currently investigates these issues in a study about German policy-making. In an expert interview design, mechanisms that prevent health politics from long-term thinking and comprehensive policy-making are assessed and possibilities for improvement are discussed.

Second, it would be very useful to develop a Healthcare System Sustainability Index, which would allow for a comparison of countries in terms of different aspects of sustainability as well as their overall level of sustainability. One could imagine the application of the Delphi method, where expert panel rounds provide information in a structured process, in order to select appropriate indicators [58]. Since it is difficult to evaluate whether certain institutional arrangements are more or less sustainable, it might be beneficial to examine the outputs and outcomes of systems. This could be the starting point for analyses of best-practice solutions that could guide future reforms. Of course, these kinds of analyses would have to consider the importance of country-specific path dependencies, as social, ecological, political, cultural, or historical contexts may have caused different understandings of performance in different countries [59]. Furthermore, one must take into account the multiple interdependencies between the different categories to measure sustainability that may make it more difficult to find clear quantitative indicators of the qualitative categories that were presented in this article. Moreover, it could be problematic to equate lower numbers in certain categories, for example lower costs, with higher levels of sustainability because fewer resources do not always mean better results. These kinds of questions need to be addressed in order to create a valid and reliable model to measure sustainability in healthcare systems. First steps in 
the direction of sustainability assessment can be observed on a smaller level, one of which is the Program Sustainability Assessment Tool developed by Luke et al. [60]. The program was developed after transferring the results of a literature review [61] into a questionnaire that serves as an assessment tool to rate the sustainability of public health programs. An analogous procedure aiming at the development of an assessment tool on a system-based level would be a huge step towards an improved sustainability of healthcare systems.

\section{Acknowledgments}

The author would like to thank the two anonymous reviewers for their useful comments.

\section{Conflicts of Interest}

The author declares no conflict of interest.

\section{References}

1. Coiera, E.; Hovenga, E. Building a Sustainable Health System. In IMIA Yearbook of Medical Informatics: Biomedical Informatics for Sustainable Health Systems; Geissbuhler, A., Haux, R., Kulikowski, C., Eds.; Schattauer: Celle, Germany, 2007; pp. 11-18.

2. Braun, A.; Rijkers-Defrasne, S.; Zweck, A.; Butter, M.; Dumay, A.; Leis, M. Special Issue on Health Care. Healthy Ageing and the Future of Public Healthcare Systems; European Comission Directorate-General for Research: Brussels, Belgium, 2009.

3. European Commission. The European Union Explained: Public Health Improving Health for All EU Citizens; European Commission, Directorate-General for Communication: Brussels, Belgium, 2014.

4. Report of the World Commission on Environment and Development: Our Common Future. Available online: http://www.un-documents.net/our-common-future.pdf (accessed on 12 December 2014).

5. Arah, O.A.; Westert, G.P.; Hurst, J.; Klazinga, N.S. A conceptual framework for the OECD health care quality indicators project. Int. J. Qual. Health Care 2006, 18 (Suppl. 1), 5-13.

6. Faezipour, M.; Ferreira, S. Applying systems thinking to assess sustainability in healthcare system of systems. IJSSE 2006, 2, 290-308.

7. Berman, P. Health sector reform: Making health development sustainable. Health Policy 1995, 32, $13-28$.

8. Hudson, C.G.; Vissing, Y.M. Sustainability at the Edge of Chaos: Its Limits and Possibilities in Public Health. BMRI 2013, 2013, Article 801614.

9. Mackay, R.; Wolbring, G. Sustainable Consumption of Healthcare: Linking Sustainable Consumption with Sustainable Healthcare and Health Consumer Discourses. Available online: http://www.sciforum.net/conference/wsf3/paper/2162 (accessed on 12 December 2014).

10. World Health Organization (WHO). The World Health Report 2000. Health Systems: Improving Performance; WHO: Geneva, Switzerland, 2000.

11. Grad, F.P. The Preamble of the Constitution of the World Health Organization. Bull. World Health Organ. 2002, 80, 981-982.

12. Plsek, P.E.; Greenhalgh, T. The challenge of complexity in health care. BMJ 2001, 323, 625-628. 
13. Muzyka, D.; Hodgson, G.; Prada, G. The Inconvenient Truths about Canadian Health Care. Available online: http:/www.conferenceboard.ca/cashc/research/2012/inconvenient_truths.aspx (accessed on 12 December 2014).

14. Harrison, A.; Dixon, J.; New, B.; Judge, K. Funding the NHS. Is the NHS sustainable? BMJ 1997, 314, 296-298.

15. Henke, K.D.; Schreyögg, J. Towards Sustainable Health Care Systems: Strategies in Health Insurance Schemes in France, Germany, Japan and The Netherlands; International Social Security Association: Geneva, Switzerland, 2005. (In German)

16. Lewis, S.; Donaldson, C.; Mitton, C.; Currie, G. The future of health care in Canada. BMJ 2001, 323, 926-929.

17. Jameton, A.; McGuire, C. Toward sustainable health-care services: Principles, challenges, and a process. IJSHE 2002, 3, 113-127.

18. Schön, R. Nachhaltiges Gesundheitswesen. Für eine gesunde Zukunft, für ein zukunftsfähiges Gesundheitswesen; Zentrum BATS: Zurich, Switzerland, 2004. (In German)

19. Alliance for Natural Health (ANH). Sustainable Healthcare-Working Towards the Paradigm Shift. White Paper (June 2010 Update); Alliance for Natural Health: Dorking, UK, 2010.

20. Grunwald, A.; Kopfmüller, J. Nachhaltigkeit; Campus: Frankfurt am Main, Germany, 2006. (In German)

21. Prada, G. Sustainability: What Does This Mean for Canada's Health Care Systems. In Proceedings of the Collaborative Meeting of the Conference Board of Canada's Health-Related Executive Networks, Toronto, ON, Canada, 16 April 2012.

22. Faezipour, M.; Ferreira, S. A system dynamics perspective of patient satisfaction in healthcare. Procedia Comput. Sci. 2013, 16, 148-156.

23. European Commission. Sustainable Development in the European Union-2011 Monitoring Report of the EU Sustainable Development Strategy; Publications Office of the European Union: Luxembourg, Luxembourg, 2011.

24. Stuart, N.; Adams, J. The Sustainability of Canada's Healthcare System: A Framework for Advancing the Debate. Healthc. Q. 2007, 10, 96-102.

25. World Health Organization (WHO). Climate Change and Health: A Tool to Estimate Health and Adaption Costs; World Health Organization Office for Europe: Copenhagen, Denmark, 2013.

26. World Health Organization (WHO). Burden of Disease from Household Air Pollution for 2012. Summary of Results. Available online: http://www.who.int/phe/health_topics/outdoorair/databases /FINAL_HAP_AAP_BoD_24March2014.pdf (accessed on 12 December 2014).

27. Keune, H.; Kretsch, C.; de Blust, G.; Gilbert, M.; Flandroy, L.; van den Berge, K.; Versteirt, V.; Hartig, T.; de Keersmaecker, L.; Eggermont, H.; et al. Science-policy challenges for biodiversity, public health and urbanization: Examples from Belgium. Environ. Res. Lett. 2013, 8, 1-19.

28. Prada, G.; Brown, T. The Canadian Health Care Debate: A Survey and Assessment of Key Studies; The Conference Board of Canada: Ottawa, ON, Canada, 2012.

29. Prada, G.; Grimes, K.; McCleery, A.; Nguyen, D.; Pomey, M.P.; Reed, V.; Stonebridge, C.; Roberts, G. Challenging Health Care System Sustainability. Understanding Health System Performance of Leading Countries; The Conference Board of Canada: Ottawa, ON, Canada, 2004. 
30. Macino, J.; Starfield, B.; Shi, L. The contributon of primary care systems to health outcomes within Organization for Economic Cooperation and Development (OECD) countries, 1970-1998. Health Serv. Res. 2003, 38, 831-865.

31. Rapoport, J.; Jacobs, P.; Bell, N.R.; Klarenbach, S. Refining the Measurement of the Economic Burden of Chronic Disease in Canada. Chronic Dis. Can. 2004, 25, 13-21.

32. Thorpe, K.E.; Howard, D.H. The rise in spending among Medicare beneficiaries: The role of chronic disease prevalence and changes in treatment intensity. Health Affair. 2006, 25, w378-w388.

33. Morgan, M.W.; Zamora, N.; Hindmarsh, M.F. An inconvenient truth: A sustainable healthcare system requires chronic disease prevention and management transformation. Healthc. Papers 2007, 7, 6-23.

34. Baumann, A.; O’Brien-Pallas, L.; Armstrong-Stassen, M.; Blythe, J.; Bourbonnais, R.; Cameron, S.; Irvine Doran, D.; Kerr, M.; McGillis Hall, L.; Vezina, M.; et al. Commitment and Care: The Benefits of a Healthy Workplace for Nurses, Their Patients and the System; Canadian Health Services Research Foundation: Ottawa, ON, Canada, 2001.

35. Institute of Medicine. Medicare: A Strategy for Quality Assurance. Volume I; National Academy Press: Washington, DC, USA, 1990.

36. Donabadian, A. Evaluating the quality of medical care. Milbank Mem. Fund Q. 1966, 44, 166-206.

37. Weiser, T.G.; Regenbogen, S.E.; Thompson, K.D.; Haynes, A.B.; Lipsitz, S.R.; Berry, W.R.; Gawande, A.A. An estimation of the global volume of surgery: A modelling strategy based on available data. Lancet. 2008, 372, 139-144.

38. Organisation for Economic Co-operation and Development (OECD). Geographic Variations in Health Care: What Do We Know and What can be Done to Improve Health System Performance? OECD Health Policy Studies; OECD Publishing: Paris, France, 2014.

39. Brulle, R.J.; Pellow, D.N. Environmental justice: Human health and environmental inequalities. Annu. Rev. Public Health. 2006, 27, 103-124.

40. Leiserowitz, A.A.; Kates, R.W.; Parris, T.M. Sustainability values, attitudes, and behaviors: A review of multinational and global trends. Annu. Rev. Environ. Resour. 2006, 31, 413-444.

41. Heinrichs, H.; Laws, N. "Sustainability State" in the Making? Institutionalization of Sustainability in German Federal Policy Making. Sustainability 2014, 6, 2623-2641.

42. Dahlgren, G.; Whitehead, M. Policies and Strategies to Promote Equity in Health; World Health Organization: Copenhagen, Denmark, 1991.

43. Dahlgren, G.; Whitehead, M. Tackling inequalities in health: What can we learn from what has been tried? In Working Paper Prepared for the King's Fund International Seminar on Tackling Inequalities in Health, September 1993, Ditchley Park, Oxfordshire; King's Fund (Mimeo): London, UK, 1993.

44. European Commission. Impact Assessment Board Report for 2013. Available online: http://ec.europa.eu/smart-regulation/impact/key_docs/docs/iab_report_2013_en.pdf (accessed on 12 December 2014).

45. Prüss-Üstün, A.; Corvalán, C. Preventing Disease through Healthy Environments. Towards an Estimate of the Environmental Burden of Disease; WHO: Geneva, Switzerland, 2006.

46. Greene, V.W. Reuse of Disposable Medical Devices: Historical and Current Aspects. Infect. Control 1986, 7, 508-513. 
47. Kümmerer, K. Pharmaceuticals in the environment. Annu. Rev. Env. Resour. 2010, 35, 57-75.

48. Harvey, A.L. Natural products in drug discovery. Drug Discov. Today 2008, 13, 894-901.

49. Newman, D.J.; Kilama, J.; Bernstein, A.; Chivian, E. Medicines from nature. In Sustaining Life: How Human Health Depends on Biodiversity; Chivian E., Bernstein A., Eds.; Oxford University Press: New York, NY, USA, 2008; pp. 117-162.

50. Randolph, S.E.; Dobson, A.D.M. Pangloss revisited: A critique of the dilution effect and the biodiversity-buffers-disease paradigm. Parasitology 2012, 139, 847-863.

51. Götz, K.; Deffner, J. Options for a More Environmentally Friendly Handling of Pharmaceuticals. In Green and Sustainable Pharmacy; Kümmerer, K., Hempel, M., Eds.; Springer: Berlin, Germany, 2010; pp. 149-163.

52. Collier, R. The ethics of reusing single-use devices. CMAJ 2011, 183, Article 1245.

53. Weinstein, M.C.; Skinner, J.A. Comparative Effectiveness and Health Care Spending-Implications for Reform. N. Engl. J. Med. 2010, 362, 460-465.

54. Agenda 21. United Nations Conference on Environment and Development Rio de Janeiro, Brazil, 3 to 14 June 1992. Available online: http://sustainabledevelopment.un.org/content/documents/ Agenda21.pdf (accessed on 12 December 2014).

55. Lifvergren, S.; Docherty, P.; Shani, A.B.R. Chapter 4 towards a sustainable healthcare system: Transformation through participation. In Organizing for Sustainable Effectiveness; Mohrman, S.A., Shani, A.B.R., Worley, C., Eds.; Emerald Group Publishing: Bingley, UK, 2011; pp. 99-125.

56. Mohrman, S.A.; Shani, A.B.R.; McCracken, A. Chapter 1 Organizing for sustainable healthcare: The emerging global challenge. In Organizing for Sustainable Health Care (Organizing for Sustainable Effectiveness); Mohrman, S.A., Shani, A.B.R., Eds.; Emerald Group Publishing: Bingley, UK, 2012; pp. 1-39.

57. World Economic Forum (WEF). Sustainable Health Systems. Visions, Strategies, Critical Uncertainties and Scenarios. A report from the World Economic Forum Prepared in Collaboration with McKinsey \& Company; World Economic Forum: Geneva, Switzerland, 2013.

58. Boulkedid, R.; Abdoul, H.; Loustau, M.; Sibony, O.; Alberti, C. Using and reporting the Delphi method for selecting healthcare quality indicators: A systematic review. PLoS One 2011, 6, Article e20476.

59. Pringle, M.; Wilson, T.; Grol, R. Measuring "goodness" in individuals and healthcare systems. BMJ 2002, 325, 704-707.

60. Luke, D.A.; Calhoun, A.; Robichaux, C.B.; Elliott, M.B.; Moreland-Russell S. The Program Sustainability Assessment Tool: A New Instrument for Public Health Programs. Prev. Chronic Dis. 2014, 11, Article 130184.

61. Schell, S.F.; Luke, D.A.; Schooley, M.W.; Elliot, M.B.; Herbers, S.H.; Mueller, N.B.; Bunger, A.C. Public health program capacity for sustainability: A new framework. Implement. Sci. 2014, 8, Article 15.

(C) 2014 by the authors; licensee MDPI, Basel, Switzerland. This article is an open access article distributed under the terms and conditions of the Creative Commons Attribution license (http://creativecommons.org/licenses/by/4.0/). 